\title{
Os menores na leitura e os pormenores na escrita de Antonio Candido
}

\author{
Simone Guimarães Matheus*
}

\begin{abstract}
RESUMO
A partir de palestras e ensaios a respeito do crítico literário Antonio Candido, produzidos por dois outros grandes críticos brasileiros, objetivamos, com este trabalho, promover uma discussão acerca do que os autores desses artigos pensavam e pensam sobre a contribuição para a literatura brasileira desse crítico, levando em consideração, sobretudo, os conceitos, os ensaios e a perspectiva mais fecundos do homenageado para o cenário crítico atual. A escrita neste ensaio foi fiel às pontuações feitas pelos dois críticos literários e professores da USP: Prof. PhD Adélia Bezerra de Meneses e Prof. Dr. Davi Arrigucci Júnior. A novela "A estória de Lélio e Lina", de Guimarães Rosa (2001), principalmente um caso oral que é relatado dentro dessa novela, servirá como uma tentativa de exemplificação dos pontos seminais da vasta teoria defendida pelo crítico Antonio Candido.
\end{abstract}

Palavras-chave: Antonio Candido. Crítica. Literatura. Humanizadora. Sistema.

Pontifícia Universidade Católica de Minas Gerais (PUC Minas). Mestre em Estudos Literários pela Universidade Federal de Minas Gerais. Doutoranda em Literaturas de Língua Portuguesa no Programa de pósgraduação em Letras da PUC Minas. Bolsista Capes. 


\title{
The Smallest in Reading na the Details in Writing by Antonio Candido
}

\begin{abstract}
From lectures and essays about the literary critic Antonio Candido, produced by two great names of Brazilian critics, we aim, with this work, to promote a discussion about what the authors of these articles thought and think about the contribution to the Brazilian literature of this critic, taking into account, above all, the most fruitful concepts, essays and perspective of the honor for the current critical scenario. The writing in this essay was true to the scores made by the two USP literary critics and teachers: PhD Adélia Bezerra de Meneses and Prof. Dr. David Arrigucci Junior. Guimarães Rosa’s novel "The Story of Lélio e Lina" (2001), mainly an oral case that is reported within this novel, will serve, in the attempt, as an example of seminal points in the vast theory defended by the critic Antonio Candido.
\end{abstract}

Keywords: Antonio Candido. Critical. Literature. Humanizing. System. 
Ao iniciarmos uma das disciplina obrigatórias do Curso de Pós-Graduação de Letras da PUC Minas, fomos surpreendidos com uma aula inaugural em homenagem ao ilustre professor, intelectual, crítico literário, pensador do Brasil, militante, Antonio Candido, proferida por Adélia Bezerra de Menezes, ${ }^{1}$ que, emocionada, lembrava que, em maio de 2017, a voz física do mestre se calou, mas não o seu pensamento.

Carinhosamente, a professora da USP compartilhou algumas anotações feitas em um caderno ainda em caneta tinteiro da primeira aula com o ilustre professor. Uma das primeiras definições de literatura anotada nesse caderno impactou não só a então caloura, em 1962, mas a todos nós, espectadores, pois há, nessa definição atemporal, um potencial mobilizador extraordinário: "Disciplina humanizadora que torna o homem capaz não de se ajustar, mas de se sentir suficientemente inquieto para mudar o seu tempo.". 2

A palestrante, dando sequência à aula, questiona o que mais marcaria essa personalidade do criador da teoria literária: a inteligência poderosa ou a força da sua generosidade atuante não só na relação individual, mas também em termos de sociedade. Para ela, ele via o outro social, pensava o Brasil e o mundo no recorte da polis, no recorte da cidade. Assim, vê sua militância para intervir nas estruturas, tendo participado da formação de dois partidos políticos de viés socialista. Em 1947, ele foi um dos fundadores do Partido Socialista e, em 1980, do Partido dos Trabalhadores (PT).

1 Palestra da professora Adélia Bezerra de Meneses, em homenagem a Antonio Candido, para a PUC Minas (HOMENAGEM, 2017).

2 Definição de literatura citada pela palestrante a partir do seu caderno de anotações das aulas do professor Antônio Candido. 
É dessa mesma fonte socialista, dessa generosidade social do seu pensamento, que Antonio Candido cunhou a categoria de "Pensamento Radical", nas suas análises da cultura brasileira, focando atenção não na classe dominante, mas no povo. Esse pensamento tem como característica a ruptura da tradição elitista do nosso pensamento social:

\begin{abstract}
Portanto, no que tem de positivo o radical serve à causa das transformações viáveis em sociedades conservadoras como a nossa, cheias de sobrevivências oligárquicas, sujeitas ainda por muito tempo à interferência periódica dos militares. O radicalismo seria um corretivo da tendência predominante nessas sociedades, que consiste em canalizar as reivindicações e as reformas, deformando-as por meio de soluções do tipo populista, isto é, as que manipulam o dinamismo popular a fim de contrariar os interesses do povo e manter o máximo possível de privilégios e vantagens das camadas dominantes. (CANDIDO,2010 p. 5).
\end{abstract}

Segundo Antonio Candido, o radical pode assumir um papel significativo para suscitar uma consciência política, abrindo caminho para uma ação revolucionária. Para o pensamento radical, o avanço significaria o atendimento às reivindicações populares por meio de um regime em que o próprio povo tomasse as rédeas. É uma posição política, segundo Candido, que teve em Sérgio Buarque, um dos primeiros intelectuais a defendê-la, em Raízes do Brasil.

Diante disso, pode-se perceber, por meio da palestra da professora Adélia, que o intelectual radical, sociólogo dublado em crítico literário, ajudou e continua contribuindo a entender este país. Ele abordou a literatura como sistema, mostrando a relação entre literatura e sociedade, dirigindo o olhar às coisas brasileiras devidamente equacionadas em seu quadrante universal, apontando-a como um fator humanizador. 
Esse argumento da função humanizadora da literatura é recorrente no pensamento e na práxis do militante esteta e é pontuado, também, em um dos seus textos seminais, um dos grandes ensaios do autor que exprime algo de fundamental e que marcou uma cultura não apenas no Brasil, mas também no mundo: a literatura como um dos direitos humanos fundamentais. Antonio Candido parte da própria dificuldade em discriminar o que é essencial ou não em termos de direitos humanos:

\begin{abstract}
Penso na sua distinção entre "bens compressíveis" e "bens incompressíveis", que está ligada a meu ver com o problema dos direitos humanos, pois a maneira de conceber a estes depende daquilo que classificamos como bens incompressíveis, isto é, os que não podem ser negados a ninguém. Certos bens são obviamente incompressíveis, como o alimento, a casa, a roupa. Outros são compressíveis, como os cosméticos, os enfeites, as roupas supérfluas. Mas a fronteira entre ambos é muitas vezes difícil de fixar, mesmo quando pensamos nos que são considerados indispensáveis. (CANDIDO, 2004, p. 169).
\end{abstract}

Há, no entanto, "necessidades que não podem deixar de ser satisfeitas sob pena de desorganização pessoal, ou pelo menos de frustração mutiladora.” (CANDIDO, 2004, p. 3). A literatura corresponde a uma necessidade universal e "confirma no homem a sua humanidade, fazendo a gente exercer aquilo que faz de nós fundamentalmente seres humanos." (CANDIDO, 2004, p. 6).

Nesse mesmo ensaio, o autor cita alguns itens que confirmam no homem sua humanidade:

Entendo aqui por humanização (já que tenho falado tanto nela) o processo que confirma no homem aqueles traços que reputamos essenciais, como o exercício da reflexão, a aquisição do saber, a boa disposição para com o próximo, o afinamento das emoções, a capacidade de penetrar nos problemas da vida, o senso da beleza, a 
percepção da complexidade do mundo e dos seres, o cultivo do humor. A literatura desenvolve em nós a quota de humanidade na medida em que nos torna mais compreensivos e abertos para a natureza, a sociedade, o semelhante. (CANDIDO, 2004, p. 169).

O autor aponta que um objeto construído - a literatura só atua a partir da sua forma. É a forma que traz virtualmente a capacidade de humanização. Um poema, por exemplo, funciona nos presentando um tipo de ordem e sugerindo um modelo de superação do caos, mesmo que esse processo se dê no nível inconsciente. Portanto, ao colocar em palavras, nomear emoções e situações existenciais confusamente vividas e, até então, inarticuladas, a literatura promove uma passagem do caos de sentimentos e percepções a um cosmos. "Toda obra literária é antes de mais nada uma espécie de objeto, de objeto construído; e é grande o poder humanizador desta construção, enquanto construção.” (CANDIDO, 2004, p. 72). Por meio da eficácia formal da poesia, ela passa de vivência do indivíduo para experiência do ser humano, em que todos nós possamos nos reconhecer e com a qual podemos nos identificar.

Em “A estória de Lélio e Lina", de Guimarães Rosa (2001), uma das novelas de No Urubuquaquá, no Pinhém, Guimarães Rosa trata, metaliterariamente, do poder humanizador do texto literário, a partir da atuação da literatura em um dos personagens. Dona Rosalina uma das personagens, entendida como uma espécie de mentora para o "mocinho" Lélio, passa seus conselhos por meio de "casos", cantigas, provérbios que vão combinando com contos orais. Em momentos angustiantes, Lélio recorre sempre a dona Rosalina e, de acordo com o narrador, "A ela, sem receio nenhum, contava tudo que estava sentindo. A velhinha sabia." (ROSA, 2001, p. 247). Em um desses dias, "de desespero de remorso" vai procurar Dona Rosalina, e esta conta um caso: 
- "Na hora que Deus começa, dois vaqueiros moravam, cada um com sua mulher e seus filhos, em sendas casinhas muito perto uma da outra, numa baixada, na fazenda do Acroá-Mirim — do Urucúia em reta - vizinhando por Goiás..." Era dona Rosalina quem contava. - "...O fazendeiro dali andava muito esmorecido, porque adoecera em medo de morrer, e começava arrependimento de maldade de injustiças que tinha feito, com diversas pessoas, principalmente com os dois vaqueiros, com um e com o outro. Vai, então, numa noite, ele doido-sonhou que aqueles dois vaqueiros tinham rodado em briga de morte, e um tinha pragavado feio o ferrão na barriga do outro, que mais que o outro ainda arranjou tempo também de encravar o ferrão de sua vara por debaixo do queixo do primeiro, e os dois estavam em sangues mortos, as duas mulheres chorando, e as crianças... O fazendeiro pulou se levantou, e a pé mesmo bateu para lá, correndo junto com a madrugada, somenho nas pressas, que ia - como lá o diz - com um calço de botina mas o outro de chinelo... E tinham medrado mesmo aquela briga, ou bem: o sonho era de verdade. À rixa principiada entre dois meninos, filhos de um e de outro, depois prosseguida pelas duas mulheres, por fim os pais homens. No exato em que o fazendeiro apareceu descendo a ladeira para a baixada, e divisou a briga, e gritou ordem de paz, os dois vaqueiros estavam quando que as feras, se investindo, cada um com sua vara na mão, os ferrões total destapados. Aí, eles se apartaram, a arqueio de autoridade, não houve mortes; com pouco até fizeram congraça no cordial. Apesar do que, nesse dia, assim em segredo, um perguntou ao outro o que tinha visto primeiro, quando seo Apaulino surgira aos gritos, na vertente. Cada um tinha avistado era sua figura de pessoa mesma, em cara e corpo, feito num espelho! Assim, pensavam que tinham visto o diabo, assim tinham pensado... Mas, uns três dias depois, o fazendeiro seo Apaulino caiu numa pirambeira, de alturas enormes, foi achado lá em baixo expirado no cair tinha rebentado uma árvore seca, uma ponta de galho o espichara pelo mole da barriga, outro furara no sobqueixo, surto..." Dona Rosalina rematava as experiências, a glosa: - "Sempre há remorso na gente, enquanto um vive. $\mathrm{O}$ remorso não se sabe, é escondido. 
Tudo é remorso." Mas arrependimento aguentado era coisa séria, e muito rara; tão difícil, que a gente sempre devia de ter inveja de um que se arrepende brabo, em cão e cunhão. - "Quando o calor do fôgo esquenta a chaleira, meu Mocinho, tudo vai virando bolha..." Lélio queria ir procurar o Tomé, e não podia. Deixava para depois. (ROSA, 2001, p. 286).

Nesse "caso" contado a Lélio, pode perceber uma "troca de destino", como já apontado por Cavalcanti: "Sob os auspícios do diabo, que figura na elocução dos vaqueiros, seo Apaulino, para livrar-se do remorso, troca de lugar com os subalternos..." (ATROCH, 2018, p. 15). Mas, também, para nossa proposta, ajudaria pensar sobre a "reversibilidade" dos sujeitos da estória - termo cunhado pelo mestre Antonio Candido e retomado pela professora Márcia Marques Morais em muitos de seus ensaios:

Some-se a isso o fato de que essas inversões, que poderiam também ser incluídas nas reversibilidades lidas por Candido [...] não param aí: acabam atingindo autor e leitor, em mais um dos muitos desdobramentos daquela "operação de alta estética" ou "esquema técnico", a que me referi. (MORAIS, 2006).

Chama a atenção quantas vezes aparece as palavras que denotam a ambiguidade do sujeito:

cada um com sua mulher e seus filhos [...] muito perto uma da outra [...] principalmente com os dois vaqueiros, com um e com o outro [...] e um tinha pragavado feio o ferrão na barriga do outro, que mais que o outro ainda arranjou tempo também de encravar o ferrão de sua vara por debaixo do queixo do primeiro, e os dois estavam em sangues mortos, as duas mulheres chorando, e as crianças... [...] filhos de um e de outro [...] cada um com sua vara na mão... [...] Cada um tinha avistado era sua figura de pessoa mesma, em cara e corpo, feito num espelho! (ROSA, 2001, p. 286, grifo nossos). 
Assim, abre-se a possibilidade aqui, a partir da análise desses pormenores inscritos na forma, de percebermos a reversibilidade das personagens que apontam para essa visada especular: o chefe Apaulino caiu e foi atingido embaixo do queixo e na barriga, exatamente nos pontos que os vaqueiros seriam atingidos. Além dessa troca de lugar entre o chefe e os vaqueiros, os vaqueiros também se alternam, na ambiguidade confirmada pela escolha desses elementos coesivos. Assim, não se sabe ao certo de qual sujeito se trata em várias predicações: de quem são os filhos, de qual mulher se está falando e, nem mesmo, de qual vaqueiro. $\mathrm{Na}$ elocução de um dos vaqueiros, o diabo é visto como se fosse um espelho deles mesmos.

$\mathrm{O}$ fato de a personagem Lina ter lhe contado uma história ambígua de conflitos e remorsos agudos de todas as personagens nos diz fundamentalmente da importância de a literatura, como um sistema organizado, abrir a possibilidade de uma elaboração inconsciente das ideias desarticuladas da personagem. Parafraseando a afirmação de Antonio Candido, privar o pobre da literatura seria uma espoliação.

Concluindo, ainda com as ideias da aula inaugural da professora Adélia de Menezes, para Antonio Candido, a literatura não é só uma força organizadora, mas é também humanizadora e, portanto, todos deviam ter acesso a ela. A literatura fornece a possibilidade de expressão simbólica de percepções, afetos e sentimentos não formulados, mas confusamente vividos. Ela faculta a possibilidade de uma tradução desse mundo desarticulado em palavra. "Ela ajuda fazer passar esse vórtice interior, que é cada um de nós, à forma organizada." (HOMENAGEM, 2017).

Um outro enfoque para se pensar esse trecho da novela rosiana, também embasado no pensamento de Antonio Candido, 
seria uma análise dentro do recorte "literatura e sociedade", entendendo aqui a relação dessa obra com o solo cultural em que ela foi engendrada - denominado nos termos do teórico de "o externo", ou seja, o social -, tornando-o interno, isto é, elementos internos na estrutura do texto rosiano. Assim, podemos ver que todo o enredo da história contada a Lélio é uma história de briga de morte. Briga essa que tem um valor simbólico: o enredo do caso se sustenta nesse impedimento de que ocorra uma morte anunciada em sonho ao fazendeiro seo Apaulineo.

O patrão que tem nome "Apaulineo" evoca "Apolíneo", sabendo que Apolíneo e Dionisíaco é um conceito filosófico e literário que define uma dicotomia com base em certas características da antiga mitologia grega. ${ }^{3} \mathrm{O}$ Apolíneo é o lado da razão e do raciocínio lógico. Por outro lado, o Dionisíaco é o lado do caos e apela para as emoções e instintos. Entretanto, vêse aqui a personagem com características mais relativas ao caos, apelando para o instinto, acreditando em sonhos e terminado de uma forma trágica: “ele doido-sonhou”. (ROSA, 2001, p. 286).

Agora, seguindo os conceitos do nosso autor homenageado, analisaremos o "externo", ou seja, o social, o que encontramos na sociedade brasileira na década de 50. De acordo com a ilustração que Albuquerque (1999) faz daquele momento:

O retorno de Vargas (1951-1954) teve mais clareza em seus propósitos nacionalistas e industrializantes. A despeito do período em grande parte conflituoso com as forças reacionárias do país, avançamos ainda mais

3 Na mitologia grega, Apolo e Dionísio são ambos filhos de Zeus. Se Apolo representa as forças de ponderação e autodomínio, podemos trazer Dionísio como seu antípoda, completo oposto. Deus estrangeiro, asiático e misterioso, Dionísio representa a potência de ruptura e dissolução das fronteiras. Enquanto Apolo fica do lado da bela individualidade, do onírico, Dionísio carrega consigo forças orgiásticas, de rompimento completo das inibições. https://razaoinadequada.com. 
na consolidação da implantação da indústria leve e do início da marcha rumo à indústria pesada. Cerceado pela direita, Vargas se suicida em 1954, e seu gesto, tendo tido forte impacto político sobre as massas populares, certamente conseguiu adiar (para 1964) o golpe tão almejado pela direita. (ALBUQUERQUE, 1999, p.7).

É possível compreender o nome do chefe e suas atitudes desmedidas e conflituosas -“...quando seo Apaulino surgira aos gritos, na vertente." (ROSA, 2001, p. 287) - como traços que revelam essa crise de autoridade característica do fim da Era Vargas, agregando a esta pequena análise, os elementos sociais como fatores da própria construção artística, pensado no nível explicativo e não ilustrativo, conforme a metodologia sugerida pelo mestre:

Quando fazemos uma análise deste tipo, podemos dizer que levamos em conta o elemento social, não exteriormente, como referência que permite identificar, na matéria do livro, a expressão de uma certa época ou de uma sociedade determinada; nem como enquadramento, que permite situá-lo historicamente; mas como fator da própria construção artística, estudando no nível explicativo e não ilustrativo. (CANDIDO, 2010, p. 17).

Um outro importante livro do esteta homenageado que é considerado um marco nos estudos da crítica literária é Formação da literatura brasileira, de 1956. Para melhor argumentar criticamente sobre essa grande obra, recorremos a mais um mestre da crítica literária, especificamente, às ideias expostas em um ensaio intitulado "Questões sobre Antonio Candido" (ARRIGUCCI, 2010), no qual há apontamentos sobre os conceitos centrais e fecundos dessa obra.

Arrigucci inicia o texto em tom confessional, desabafando a escassez crítica com a qual se deparou ao iniciar seus estudos das 
obras literárias na década de sessenta, embora o autor relate, em seguida, o quão emocionado ficou ao cair em suas mãos estudos de Erich Auerbach, Leo Spitzer e Dámaso Alonso. Mas o livro decisivo para abrir (não só para o autor) os estudos literários a uma reflexão sobre a literatura moderna foi o referido livro de Antonio Candido. A partir de Candido, houve uma reflexão não só sobre a literatura moderna, mas também sobre os problemas teóricos-críticos da teoria literária e da literatura comparada. "A sua nova concepção de história da literatura apresentada na Formação da literatura brasileira alterou definitivamente a visão do nosso passado literário.” (ARRIGUCCI, 2010, 116).

Nos nossos dias, parece transposto o perigo de submissão ao estudo dos fatores básicos, sociais e psíquicos. Houve tempo, com efeito, em que o crítico cedeu lugar ao sociólogo, ao político, ao médico, ao psicanalista. Hoje, o perigo vem do lado oposto; das pretensões excessivas do formalismo, que importam, nos casos extremos, em reduzir a obra a problemas de linguagem, seja no sentido amplo da comunicação simbólica, seja no estrito sentido da língua. (CANDIDO, 2000, p. 32).

É fundamental a concepção do texto como resultado que perpassa todas as análises que se encontram ao longo de Formação da literatura brasileira, mesmo que escrito em uma perspectiva histórica. Essa concepção, do texto como resultado, é que proporciona uma autonomia ao texto literário sem dispensar os fatores externos, tais como os psíquicos e os sociais. Essa concepção, cunhada por Antonio Candido, ressalta Arrigucci, é integradora, pois permite analisar os textos literários em sua particularidade sem deixar de considerar a pertinência estética dos fatores histórico-sociais. Por meio desse viés crítico, ele conseguiu o feito de superar tanto o formalismo quanto o reducionismo sociológico. 
Outro conceito, considerado por Arrigucci como fundamental, pois rege a perspectiva da crítica quando se embasa no ponto de vista histórico, é o conceito da tradição:

\begin{abstract}
Quando a atividade dos escritores de um dado período se integra em tal sistema, ocorre outro elemento decisivo: a formação da continuidade literária, espécie de transmissão da tocha entre corredores, que assegura no tempo o movimento conjunto, definindo os lineamentos de um todo. É uma tradição, no sentido completo do termo, isto é, transmissão de algo entre os homens, é o conjunto de elementos transmitidos, formando padrões que se impõem ao pensamento ou ao comportamento, e aos quais somos obrigados a nos referir, para aceitar ou rejeitar. Sem esta tradição não há literatura, como fenômeno de tradição. (CANDIDO, 2000, p. 24).
\end{abstract}

Por meio da tradição, exprime-se o sentido histórico mais profícuo do processo pelo qual as obras se aceitam ou se articulam no tempo, mediante a assimilação do passado e a invenção das novas formas em correspondência com os novos contextos que cada época traz, explica Arrigucci.

Ainda ressaltando a fecundidade da crítica de Antonio Candido, Arrigucci aponta como o crítico, junto com o narrador, acompanha como se dá o tratamento dos pormenores em determinados textos ficcionais e, a partir daí, cunha uma ideia nova, a do "transrealismo", que seria uma espécie de libertação do registro do real, a partir da liberdade de imaginação na utilização de cada detalhe. Por isso mesmo, percebe-se o motivo pelo qual há a valorização da metáfora na crítica de Candido, pois por meio dela é que se enlaçam as similitudes e se desenha a importância dos pormenores.

Retomemos, na íntegra, as palavras contundentes do professor: 
Até hoje é difícil imaginar um instrumento de trabalho mais fino, abrangente e adequado à compreensão do texto literário do que esse que Antonio Candido elaborou com sua proposta teórica e sua incomparável prática de analista de textos, da qual depende, na verdade, a construção de sua teoria. Isso demonstra que antes de tudo ele é um extraordinário leitor, cujo olhar arguto, sensível e imaginativo sabe captar todo pormenor significativo de uma obra sem perder a mobilidade que lhe dá a compreensão histórica. (ARRIGUCCI, 2010, p.119).

Tanto a ideia da literatura como função humanizadora, como a do direito à literatura, foram fortemente defendidas por Antonio Candido. Por isso, encerramos nosso artigo com um exemplo da vida real do próprio mestre dos mestres:

A propósito: a professora Maria Vitória Benevides me contou que há alguns anos a prefeitura de Milão resolveu exigir que os industriais dessem algumas horas livres cada semana para os operários poderem se instruir, certa de que cada setor escolheria o aperfeiçoamento nas técnicas da sua profissão. No entanto, a maioria absoluta pediu cursos de língua italiana e a leitura explicada do grande poema de Dante Alighieri A divina comédia, uma das obras supremas da inteligência humana. $\mathrm{Na}$ Itália há milhares de pessoas de todas as classes que sabem de cor partes dele, o que verifiquei quando menino na minha cidade de Poços de Caldas. Havia lá um velho sapateiro florentino, Crispino Caponi, que memorizara toda a primeira parte do poema, "O inferno", constituído por 34 cantos num total de mais ou menos 5 mil versos. A oficina dele era na praça central e ele passava o dia batendo as suas solas perto da porta. As pessoas lhe pediam para recitar o canto número tal e, se estivesse de bom humor (o que não era freqüente), ele o dizia com a pureza toscana de Dante, florentino como ele. Para mim, o velho e rabugento Crispino ficou sendo um exemplo de como a mais alta literatura pode ser apreciada pelo trabalhador e como este pode usar bem o seu tempo além da tirania das tarefas. (CANDIDO, 2004. p.170). 
Destarte, não custa reforçar que "[...] a leitura nos refina e nos liberta de muitas servidões." (CANDIDO, 2004.p 191).

\section{Referências}

ALBUQUERQUE, Wlamyra R. de. Algazarra nas ruas: comemorações da independência na Bahia (1889-1923). Campinas: Unicamp, 1999.

ARRIGUCCI JR., Davi. Questões sobre Antonio Candido. In: ARRIGUCCI JR., Davi. O guardador de segredos: ensaios. São Paulo: Companhia das Letras, 2010. p. 115-119.

ATROCH, Daniel Cavalcanti. Grande sertão: veredas: diabo, pacto e destino. 2018. Tese (Doutorado em Teoria Literária e Literatura Comparada) - Universidade de São Paulo, São Paulo, 2018.

CANDIDO, Antonio. Dialética da malandragem: o discurso e a cidade. São Paulo: Duas Cidades, 1998. p. 19-54.

CANDIDO, Antonio. Formação da literatura brasileira: momentos decisivos. 6. ed. Belo Horizonte: Itatiaia, 2000. 2 v.

CANDIDO. A. Jagunços mineiros de Cláudio a Guimarães Rosa. In: CANDIDO, Antonio. Vários escritos. 3. ed. São Paulo: Duas Cidades, 1995.

CANDIDO, Antonio. Literatura e sociedade: estudos de teoria e história literária. 11. ed. Rio de Janeiro: Ouro sobre azul, 2010. CANDIDO, Antonio. O homem dos avessos. In: CANDIDO, Antonio. Tese e antítese. São Paulo: Cia Editora Nacional, 1978. p. 119-139.

CANDIDO, Antonio. Vários escritos. 4. ed. São Paulo: Ouro sobre azul, 2004. p. 169-191. 
HOMENAGEM a Antonio Candido. Palestra de Adélia Bezerra de Meneses. Belo Horizonte: PUC Minas, 4 dez. 2017. 1 vídeo (51 min). Publicado por Pedro B. de Meneses Bolle. Disponível em: <https://youtu.be/vUkExr7hUBk>. Acesso em: 5 jul. 2019.

MORAIS, Márcia Marques de. A travessia dos fantasmas: literatura e psicanálise em Grande sertão: veredas. Belo Horizonte: Autêntica/ PUC Minas, 2001. 175 p.

MORAIS, Márcia Marques de. Do nome-da-mãe ao nome-dopai: figuração de identidades no "Grande sertão". Scripta, Belo Horizonte, v. 5, n. 10, p. 264-273, 1. sem. 2002.

MORAIS, Márcia Marques de. O romance se fez letra: a metaliteratura em Grande sertão: veredas. O eixo e a roda: revista de literatura brasileira, Belo Horizonte, v. 12, p. 203214, 2006.

RONCARI, Luiz. O Brasil de Rosa: mito e história no universo rosiano: o amor e o poder. São Paulo: Editora UNESP, 2004.

ROSA, J. G. No Urubuquaquá, no Pinhém. Rio de Janeiro: Nova Fronteira, 2001. 